\title{
MENINGKATKAN MINAT BELAJAR FISIKA SMP DAN SMK NUSA BHAKTI SAWANGAN DEPOK MELALUI TEKNOLOGI MEDIA ROBOTIK
}

\author{
Dwi Aprillia Setia Asih ${ }^{1}$, Indica Yona Okyranida ${ }^{2}$, Deden Ibnu Aqil ${ }^{3}$ \\ ${ }^{1,2,3}$ Prodi Pendidikan Biologi, Universitas Indrapasta PGRI, Jakarta 13760, Indonesia \\ Email: Foton.me@gmailcom, indicaoky@gmail.com, den.aqil@gmail.com
}

\begin{abstract}
In order to increase the interest in learning physics in SMP and SMK Nusa Bhakti Sawangan Depok through robtik media, an introduction was made to the making of robotic media using line follower and robot soccer robots. The method used is to provide information in making robotic media line follower and robot soccer robots. The material provided during the workshop included the creation, management and utilization of learning media in the form of robotic media. After the activity was finished the students were given a questionnaire to determine the response of students' interest in the learning media used. From the results of this activity the results of student responses to learning media used in good categories are seen from the total score of all students, namely 1098 from the total score of 1500, in other words the interest in learning physics increases when learning activities use line follower robots and robot soccer as learning media. Then the students were enthusiastic during the activity, listening and paying attention to the explanation of the community service team and being active and happy during the process of the experimental activities. And teachers can also use robotic media to be an alternative learning media.
\end{abstract}

Keywords: Interest in Learning; Technology; Robotic Media

\begin{abstract}
Abstrak. Dalam rangka meningkatkan minat belajar fisika SMP dan SMK Nusa Bhakti Sawangan Depok melalui media robtik, dilakukan kegiatan pengenalan pembuatan media robotik menggunakan robot line follower dan robot soccer. Metode yang digunakan adalah memberikan informasi dalam membuat media robotik robot line follower dan robot soccer. Materi yang diberikan saat workshop memuat pembuatan, pengelolaan, dan pemanfaatan media pembelajaran dalam bentuk media robotik. Setelah kegiatan selesai siswa diberikan angket untuk mengetahui respon minat siswa terhadap media pembelajaran yang digunakan. Dari hasil kegiatan ini didapatkan hasil respon siswa terhadap media pembelajaran yang digunakan dalam kategori baik dilihat dari jumlah skor seluruh siswa yaitu 1098 dari jumlah skor maksimm 1500, dengan kata lain minat belajar fisika meningkat saat kegiatan pembelajaran menggunakan robot line follower dan robot soccer sebagai media pembelajaran. Kemudian Siswa antusias selama kegiatan berlangsung, mendengarkan dan memperhatikan penjelasan tim pengabdian masyarakat serta aktif dan gembira selama proses kegiatan eksperimen. Dan guru juga dapat menggunakan media robotik menjadi salah satu alternatif media pembelajaran.
\end{abstract}

Kata kunci: Minat belajar, Technology; Media Robotik

\section{PENDAHULAN}

Di era kemajuan teknologi yang menguasai pasar industri menciptakan tantangan baru bagi dunia pendidikan. Salah satunya perguruan tinggi. Pasalnya, di era ini banyak terjadi perubahan-perubahan besar sehingga menuntut berbagai elemen untuk bersiap menghadapi era teknologi termasuk pendidikan. Sementara di dunia pekerjaan akan sangat dipengaruhi oleh era kemajuan teknologi ini, akan ada banyak pekerjaan yang diambil alih oleh mesin dan robot. Hal tersebut merupakan tantangan bagi dunia pendidikan untuk menciptakan generasi penerus bangsa yang mampu bersaing dengan negara lain. Teknologi merupakan sains terapan khususnya dikalangan ilmuan dan insinyur (Donald, 2015).

Kemajuan teknologi di dunia robotika mulai dipelajari dan dikembangkan, bahkan di negara maju seperti Amerika, Jepang dan Inggris sudah mengembangkan robotika menjadi salah satu alat yang digunakan untuk mempermudahkan pekerjaan (hartono, 2003). Di Indonesia saat ini sedang mengembangkan robotika melalui ajang kompetensi di dunia, belum mengembangkannya untuk dikomersilkan. Perkembangan dunia robotika di Indonesia mulai dikenalkan pada anak-anak sejak duduk dibangku 
sekolah. Hal tersebut merupakan upaya untuk meningkatkan minat pada dunia robotika sejak dini. Saat siswa belajar robotika mereka juga mempelajari matematika, fisika dan teknologi didalamnya.

Di SMP dan SMK Nusa Bhakti Sawangan, Depok merupakan sekolahan yang letaknya strategis dan memiliki lingkungan sekolah yang nyaman untuk belajar. Guru-guru di sekolahan juga memiliki kemampuan yang baik untuk menyampaikan pembelajaran pada siswa. Namun kekurangannya di sekolahan tersebut masih belum memiliki fasilitas yang memadahi seperti peralatan laboratorium untuk praktikum siswa. Peralatan yang dimiliki sekolah banyak yang rusak, tidak lengkap dan kurang perawatannya. Hal tersebut membuat siswa dan guru tidak bisa mengembangkan ide-ide mereka melalui praktikum.

Penggunaan robot line follower dan robot soccer yang akan digunakan untuk melakukan abdimas dapat menarik siswa untuk mengasah kemampuan mereka untuk memperdalam pengetahuan mereka di dunia robotic dan membangkitkan minat mereka untuk belajar fisika, matematika dan teknologi. Berdasarkan hasil wawancara dengan guru dan dilihat dari nilai ujian siswa nilai yang paling rendah terletak pada mata pelajaran fisika.

Robot line follower dan robot soccer yang digunakan untuk pengenalan belajar robotik juga diharapkan mampu meningkatkan kreatifitas guru di sekolahan untuk mengembangkan media pembelajaran berbasis teknologi yang dapat meningkatkan minat siswa dalam belajar.

Adapun Kegiatan ini dilaksanakan dengan tujuan sebagai berikut:

1. Mengadakan kegiatan pengenalan pada siswa dalam mengembangkan robotik.

2. Mengoptimalkan fungsi teknologi dan sains yang ada di sekolah.

3. Berbagi informasi mengenai media pembelajaran berbasis teknologi.

4. Mengoptimalkan peran guru dalam mengembangkan inovasi media pembelajaran.

Solusi yang ditawarkan terhadap mitra yaitu memberikan pengenalan media robotik melalui robot line follower dan robot soccer.
Pengenalan ini dapat digunakan untuk membantu dalam menyampaikan materi terhadap siswa dan membantu menarik minat siswa. Selain itu dapat memacu kreatifitas guru dan juga siswa untuk mengembangkan kretifitasnya dalam merancang berbagai jenis robot. Selain dengan workshop, tim juga memberikan sosialisasi tentang olimpiade robotik baik tingkat nasional maupun tingkat internasional. Diharapkan dengan adanya pengenalan robot ini, ketertarikan siswa terhadap sains dan teknologi semakin besar.

Target pelaksanaan kegiatan ini adalah seluruh perangkat sekolah SMP dan SMK Nusa Bhakti Sawangan Depok, yang terdiri dari Kepala Sekolah, guru, dan karyawan serta para siswa.

Luaran yang dihasilkan dari pengabdian masyarakat ini adalah memperkenalkan kepada siswa tentang aplikasi ilmu fisika, matematika dan teknologi menjadi sebuah ilmu baru yaitu robotika. Robot line follower dan robot soccer diharapkan dapat meningkatkan minat, kreatifitas dan kemampuan berpikir siswa pada pelajaran di sekolah. Guru juga dapat menggunakan media robotic menjadi salah satu alternatif media pembelajaran. Siswa diharapkan mampu mengembangkan robot line follower menjadi berbagai macam robot di masa yang akan datang.

\section{METODE PELAKSANAAN}

Kegiatan ini dilaksanakan di SMP dan SMK Nusa Bhakti Jalan Raya Pangasisnan Blok Haji Hanin No. 31, Pengasinan, Sawangan, Depok, Jawa Barat 165118. Kegiatan ini dilaksanakan pada bulan September - Desember 2018.

Masalah yang akan dipecahkan dalam pengabdian masyarakat ini berkaitan dengan masih minimnya pemanfaatan teknologi elektronika dalam kegiatan pembelajaran di SMP dan SMK Nusa Bhakti Depok. Berbagai alternatif untuk memecahkan permasalahan tersebut dapat dilihat pada tabel 3.1. Metode yang digunakan untuk mencapai tujuan yang telah dirumuskan di atas adalah memberikan informasi dalam membuat media robotik robot line follower dan robot soccer. Materi yang diberikan saat workshop memuat pembuatan, pengelolaan, dan pemanfaatan media pembelajaran dalam bentuk media robotik. 
Tabel 3.1 Alternatif Pemecahan Masalah

\begin{tabular}{|c|c|c|}
\hline No & Permasalahan & Alternatif Pemecahan Masalah \\
\hline 1 & Pembelajaran di sekolah kurang variatif & $\begin{array}{l}\text { Pembelajaran yang dikemas dengan } \\
\text { pendekatan teknologi }\end{array}$ \\
\hline 2 & $\begin{array}{l}\text { Kemampuan dan kesempatan mengikuti } \\
\text { pelatihan pembuatan media pembelajaran } \\
\text { berbasis robotik belum pernah dilakukan. }\end{array}$ & $\begin{array}{l}\text { Memfasilitasi kesempatan untuk } \\
\text { meningkatkan inovasi pembelajaran guru } \\
\text { dalam proses pembelajaran. }\end{array}$ \\
\hline 3 & $\begin{array}{l}\text { Sekolah belum memiliki } \begin{array}{r}\text { media } \\
\text { pembelajaran penunjang berbasis } \\
\text { teknologi robotik }\end{array}\end{array}$ & Media pembelajaran berbasis robotik \\
\hline 4 & $\begin{array}{l}\text { Kurangnya minat siswa dalam pelajaran } \\
\text { IPA di SMP dan fisika di kelas di tingkat } \\
\text { SMA/SMK }\end{array}$ & $\begin{array}{l}\text { Robot line follower dan robot soccer } \\
\text { sebagai media pembelajaran penunjang } \\
\text { selain praktikum }\end{array}$ \\
\hline
\end{tabular}

Pelaksanaan kegiatan ini dilakukan dalam tiga tahap, yaitu tahap persiapan, pelaksanaan, dan evaluasi.

1. Tahap pertama adalah tahap persiapan. Dalam tahap ini tim melakukan survei pendahuluan untuk mengetahui kondisi target kegiatan dengan menganalisis kondisi tempat yang akan digunakan, kondisi peserta yang akan diberikan pelatihan, dan menyusun rancangan kegiatan yang akan dilakukan.

2. Tahap kedua yaitu tahap pelaksanaan. Tim melakukan rancang bangun line follower dan robot soccer yang ditujukan untuk seluruh perangkat sekolah SMK dan SMP Nusa Bhakti Depok. Kegiatan pelatihan ini dilakukan agar guru bisa berinovasi dalam membuat media pembelajaran sehingga bisa digunakan dalam mendukung proses kegiatan belajar mengajar.

3. Tahap ketiga adalah evaluasi. Evaluasi kegiatan ini dilakukan terhadap proses kegiatan. Evaluasi berkaitan selama kegiatan berlangsung dari tahap persiapan sampai tahap pelaksanaan, yang meliputi keadaan sekolah, kehadiran peserta pelatihan, antusias peserta saat mengikuti kegiatan, dan saran atau kritik terhadap kegiatan.

\section{HASIL DAN PEMBAHASAN}

Kesempatan mengikuti pelatihan pembuatan media pembelajaran berbasis robotik belum pernah dilakukan di sekolah SMK dan SMP Nusa Bhakti Depok. Sekolah juga belum memiliki media pembelajaran penunjang berbasis teknologi robotik. Sehingga tim pengabdian masyarakat memfasilitasi kesempatan untuk meningkatkan inovasi dalam proses pembelajaran, pembelajaran dikemas dengan pendekatan teknologi. Robot line follower dan robot soccer sebagai media pembelajaran penunjang selain praktikum.

Tim pengabdian kepada masyarakat mengajak seluruh perangkat sekolah SMP dan SMK Nusa Bhakti Sawangan Depok, yang terdiri dari Kepala Sekolah, guru, dan karyawan serta para siswa untuk mengenal komponen kelistrikan yang berkaitan dengan komponen robot line follower dan robot soccer kemudian diajak untuk membongkar dan memasang robot line follower dan robot soccer. Setelah kegiatan selesai siswa diberikan angket untuk mengetahui respon minat siswa terhadap media pembelajaran yang digunakan. Hasil respon siswa terhadap media pembelajaran yang digunakan dalam kategori baik dilihat dari jumlah skor seluruh siswa yaitu 1098 dari jumlah skor maksimm 1500, dengan kata lain minat belajar fisika meningkat saat kegiatan pembelajaran menggunakan robot line follower dan robot soccer sebagai media pembelajaran..

Hasil dari kegiatan tersebut siswa dapat menjelaskan tentang materi kelistrikan dan menjelaskan komponen-komponen yang berkaitan dengan kelistrikan serta mampu menyebutkan aplikasi konsep kelistrikan dalam kehidupan sehari-hari. Siswa antusias dalam kegiatan pembelajaran, mendengarkan dan memperhatikan penjelasan tim pengabdian masyarakat serta aktif dan gembira selama proses 
kegiatan eksperimen. Hal tersebut sebagaimana yang dikemkakan oleh Hamalik (dalam arsyad Azhar: 2007) bahwa pemakaian media pembelajaran dalam proses belajar mengajar dapat membangkitkan keinginan dan minat yang baru, membangkitkan motivasi dan rangsangan kegiatan belajar mengajar, dan bahkan membawa pengaruh-pengaruh psikologis terhadap siswa.

Luaran yang dihasilkan dari pengbdian masyarakat ini adalah seluruh perangkat sekolah SMP dan SMK Nusa Bhakti Sawangan Depok, yang terdiri dari Kepala Sekolah, guru, dan karyawan serta para siswa mengetahui tentang aplikasi ilmu fisika, dan teknlogi menjadi sebuah ilmu baru yaitu robotika. Minat belajar siswa juga meningkat saat kegiatan pembelajaran menggunakan robot line follower dan robot soccer sebagai media pembelajaran. Guru juga dapat menggunakan media robotik menjadi salah satu alternatif media pembelajaran. Setelah siswa melakukan eksperimen dengan robot line follower dan robot soccer diharapkan siswa dapat mengembangkan robot line follower dan robot soccer menjadi berbagai macam robot di masa yang akan datang.

\section{SIMPULAN DAN SARAN}

Pengabdian masyarakat yang telah dilaksanakan kepada mitra berjalan dengan baik, yaitu mitra mengetahui tentang aplikasi ilmu fisika, dan teknlogi menjadi sebuah ilmu baru yaitu robotika. Minat belajar siswa juga meningkat saat kegiatan pembelajaran menggunakan robot line follower dan robot soccer sebagai media pembelajaran. Dan guru juga dapat menggunakan media robotik menjadi salah satu alternatif media pembelajaran.

Saran yang diperlukan untuk perkembangan selanjutnya agar memperoleh media pembelajaran yang beragam, yaitu mencoba membuat media pembelajaran berbasis teknologi lainnya yang sesuai dengan kebutuhan siswa, karena kebutuhan siswa tiap kelasnya berbeda-beda.

\section{DAFTAR PUSTAKA}

Arsyad, Azhar. 2007. Media Pembelajaran. Jakarta: Raja Grafindo Persada

Donald A. MacKenzie anda Judi Wajcman. Introductory Essay in the social Shamping of technology, $2^{\text {nd }}$ ed (Buckingham, England: Open University Press,2015) ISBN 0-33519913-5

Hartono, Jogiyanto. 2003. Konsep Dasar Pemrograman Bahasa C. Yogyakarta : Andi. 